\title{
Logros lexicográficos del hispanismo serbio y el croata*
}

\section{Lexicographical achievements of Hispanic Studies in Serbia and Croatia}

\author{
ANDJELKA PEJOVIĆ \\ Universidad de Belgrado \\ andjelka.pejovic@fil.bg.ac.rs
}

Resumen: El trabajo tiene como objetivo principal presentar los logros lexicográficos bilingües del hispanismo serbio y el croata. Justificamos el tema, primero, con el hecho de que se trata de una disciplina y una parcela de estudios hispánicos muy importante, y segundo, con que hasta ahora no se haya hecho este tipo de investigación para dichas lenguas. Después de hacer una breve introducción teórica sobre la historia de la lengua española y las literaturas y culturas hispánicas en ambos países eslavos, y en particular sobre la lexicografía serbia y la croata, se procede a la presentación del corpus. El corpus se compone de los diccionarios bilingües (español-serbio/serbio-español, español-croata/croata-español) publicados en ambos países de habla eslava. Dichas obras lexicográficas se han encontrado principalmente en los catálogos de las bibliotecas nacionales y universitarias. Una vez recopilados los datos bibliográficos, se ha procedido a la consulta de los diccionarios encontrados, con el fin de clasificarlos. Finalmente, se comenta y se argumenta el cuadro obtenido y se sacan determinadas conclusiones.

Palabras clave: lexicografía bilingüe; estudios hispánicos; español; serbio, croata.

Abstract: The main objective of this paper is to present the bilingual lexicographical achievements of Hispanic Studies in Serbia and Croatia. We justify the issue, first, with the fact that it is a very important discipline and an important area of Hispanic studies, and second, that so far this type of research has not been done for these languages. After making a brief theoretical introduction to the history of the Spanish language and Hispanic literatures and cultures in respective Slavic countries, and to Serbian and Croatian lexicography, we proceed to the presentation of the corpus. The corpus is composed of bilingual dictionaries (Spanish-Serbian / Serbian-Spanish, Spanish-Croatian / Croatian-Spanish) published in respective Slavicspeaking countries. These lexicographical works have been found by searching the relevant databases, mainly in the catalogs of national and university libraries. Once the bibliographic data has been collected, the dictionaries found have been consulted, in order to classify them. Finally, we comment and argue the table obtained and we draw certain conclusions. Key words: bilingual lexicography; Hispanic studies; Spanish; Serbian; Croatian.

Fecha de presentación: 26/02/2020 Fecha de aceptación: 23/11/2020

\footnotetext{
* Este trabajo se inscribe en el proyecto de investigación 178014 Dinamika struktura savremenog srpskog jezika, financiado por el Ministerio de Educación, Ciencia y Desarrollo Tecnológico de la República de Serbia. Una primera versión de este artículo fue presentada en la conferencia internacional celebrada en la Universidad de Zagreb (Croacia) del 15 al 17 de noviembre de 2019, organizada con motivo del $100^{\circ}$ aniversario de los estudios románicos de Zagreb («100 godina zagrebačke romanistike: tradicija, kontakti, perspektive»).
} 
Los diccionarios son como los relojes: el peor es mejor que ninguno, pero del mejor uno no puede esperar que sea del todo preciso

(Samuel Johnson)

\section{INTRODUCCIÓN: OBJETIVOS, CORPUS, METODOLOGÍA}

La calidad de los diccionarios confeccionados hace 60, 80, 90 años no debería evaluarse según los criterios y las expectativas actuales, tal y como avisa Kostić-Tomović (2017: 232-233): es evidente que con el tiempo crece la brecha entre la importancia histórica de una obra lexicográfica y su aplicación, aunque la falta de nuevos diccionarios y la presencia de los diccionarios antiguos en el mercado, debido a las necesidades de los usuarios, hacen que estos necesariamente se evalúen desde la perspectiva actual.

Este trabajo tiene como objetivo principal presentar los logros lexicográficos bilingües del hispanismo serbio y el croata, sin evaluar la calidad de las obras lexicográficas existentes. Justificamos el tema, primero, con el hecho de que se trata de una disciplina y una parcela de estudios hispánicos muy importante, y segundo, con que hasta ahora no se haya hecho este tipo de investigación para dichas lenguas. Después de hacer una breve introducción teórica sobre la historia de la lengua española y las literaturas y culturas hispánicas en ambos países eslavos, y sobre la tradición lexicográfica en estos mismos países, se procede al análisis de los resultados y la presentación de las conclusiones.

El corpus en el que se basa la investigación está compuesto por los datos de los diccionarios bilingües español-serbio/serbio-español, español-croata/croata-español, publicados desde los comienzos de los estudios hispánicos en ambos países eslavos hasta hoy. Dichas obras lexicográficas se han encontrado principalmente en los catálogos de las bibliotecas nacionales y las bibliotecas universitarias. Se han incluido en el corpus todas las obras que llevan la palabra diccionario (serb. rečnik/речник, cr. rječnik) en el título o, en pocos casos, otra palabra de significado parecido. Una vez recopilados los datos bibliográficos, se ha procedido a la consulta de los diccionarios encontrados, con el fin de clasificarlos.

La lexicografía como disciplina lingüística tiene dos cometidos principales, que son, a grandes rasgos, la elaboración de diccionarios (cometido práctico) y el estudio de los productos lexicográficos y de la metodología lexicográfica (cometido teórico). En consecuencia, se distingue entre la lexicografía práctica y la lexicografía teórica o metalexicografía (Porto Dapena, 2002; Šipka, 2006). Puesto que la segunda se dedica, entre otras cosas, al estudio y el seguimiento de la práctica lexicográfica, podemos decir que este trabajo se enmarca en el campo de la metalexicografía, entendiendo la palabra en un sentido amplio.

Aunque no pretendemos hacer un análisis cualitativo ${ }^{1}$ de diccionarios particulares, sino más bien global, este análisis, no obstante, se considerará útil si se tiene en cuenta

\footnotetext{
${ }^{1}$ Para investigar la calidad de los diccionarios existentes y ver en qué medida satisfacen las necesidades de los usuarios, habría que realizar varias encuestas porque, como muestra Bratanić (1996: 45), el número y el
} 
que la competencia lexicográfica es la capacidad de un uso eficaz del diccionario, cuyo fin es encontrar la información necesaria sobre una palabra, como indica Kostić-Tomović (2017: 19). La misma autora recuerda que los componentes de la competencia lexicográfica son los siguientes: (1) la capacidad de la identificación del problema, (2) el reconocimiento de la índole lexicográfica de la información que se necesita, (3) la capacidad de elegir un diccionario adecuado, y (4) la capacidad de encontrar información en el diccionario. Por tanto, para un usuario es importante saber qué (tipos de) diccionarios tiene a su disposición, para poder elegir el o los que mejor respondan a sus necesidades. Por eso, un segundo objetivo de este trabajo consiste en hacer una lista lo más completa posible de los diccionarios publicados, español-serbio/croata, serbio/croata-español.

\section{BREVE PANORAMA DEL HISPANISMO SERBIO Y EL CROATA}

Los temas hispánicos tienen una tradición bastante larga tanto en Serbia como en Croacia. Según señala Soldatić (2011: 27), apoyándose en fuentes históricas, el principal eslabón entre Serbia y Bosnia, de un lado, y Occidente, de otro, fue Dubrovnik, por su posición geográfica y sus relaciones comerciales y navales, donde en el año 1443 fue nombrado el primer cónsul catalán. El autor también aporta datos acerca de la participación de los soldados españoles que en la primera mitad del siglo XIV (1330-1331) lucharon junto al emperador serbio Stefan Uroš III Dečanski contra los búlgaros. Considera, además, que sí existieron relaciones literarias con España, a pesar de la falta de datos.

Soldatić (2011: 27) recuerda que el pionero del hispanismo en la región de la ex Yugoslavia fue Kalmi Baruh (1896-1945), descendiente de una de las familias sefardíes más antiguas de Bosnia. Los sefardíes en general, según el autor, contribuyeron a la introducción de la lengua española y su literatura en la ex Yugoslavia, a principios del s. XX. Su labor traductora ayudó a que se conocieran obras literarias españolas, principalmente las de Cervantes ${ }^{2}$. Las traducciones anteriores prácticamente se reducen a la del Quijote. «Fue el fundador de la moderna literatura serbia, Dositej Obradović (1739-1811), quien leyó el primer Don Quijote y lo recomendó a sus compatriotas», porque «la novela cervantina es una obra que ennoblece la razón, que aumenta la perfección y la felicidad de las personas» (Stojanović, 2010: 43). No obstante, la labor traductora referente a obras en español empezó en 1885, cuando Djordje Popović tradujo La española inglesa de Cervantes: «Su traducción, en líneas generales lograda, fue un esfuerzo pionero en toda la región, dado que las demás naciones tradujeron alguna que otra novela tan solo en el siglo XX» (Stojanović, 2010: 42). El mismo autor tradujo la gran novela cervantina Don Quijote, que salió en cuatro tomos: los primeros tres en 1895, y el cuarto en 1896 (Soldatić, 2011: 29) 3 $^{3}$ La labor traductora en lo que al español se refiere no fue sistemática (Soldatić, 2011: 29). En Croacia, por su parte,

volumen de los diccionarios que existen en el mercado no muestran de manera fidedigna cuáles son las necesidades que se han cubierto.

${ }^{2}$ Kalmi Baruh tradujo del español al serbio La gloria de Don Ramiro de Enrique Larreta (en 1933) y La vorágine de José Eustasio Rivera (en 1953); Hajim Davičo tradujo dos entremeses de Cervantes («El juez de los divorcios» y «El retablo de las maravillas», en 1905); Hajim Alkalaj tradujo tres de las Novelas ejemplares de Cervantes, en 1938; etc. (Soldatić, 2011: 27-28).

${ }^{3}$ Hay una versión anterior, de 1882, pero a partir de la versión francesa (Soldatić, 2011: 29). 
había un número mayor de obras traducidas del español (Soldatić, 2011: 30), aunque la lengua oficial era el croataserbio o serbocroata.

Datos acerca de la enseñanza universitaria del español en Serbia los encontramos en Soldatić (2011: 31-34). El comienzo de los estudios del español se sitúa en el año 1951, cuando este idioma aparece como asignatura libre (facultativa) en la Facultad de Filosofía y Letras, en la Cátedra de Estudios Románicos. A partir del curso académico 1962-1963 el español tiene estatus de asignatura optativa, en el mismo departamento. Un estudio sistemático del español y la literatura escrita en español comienza en el año 1971 en la Facultad de Filología de la Universidad de Belgrado, al incorporarse un programa de lengua y literatura española de una duración de cuatro años en el seno del Departamento de estudios románicos.

En Croacia, los primeros traductores del español fueron Iso Velikanović (1869-1949), autor del primer diccionario bilingüe (1928), Josip Tabak (1912-2007), redactor de la traducción del Quijote de Iso Velikanović (considerada una de las mejores traducciones al croata) y Jakša Sedmak (Soldatić, 2011: 25). Los primeros alumnos de español se matriculan en 1968, aunque la Cátedra de lengua y literatura española fue fundada en 1961, por el famoso lingüista, traductor y académico croata Vojmir Vinja (1921-2007), uno de los especialistas en filología románica más influyentes después de la época del famoso Petar Skok ${ }^{4}$. Previamente a la fundación de la cátedra, el español se estudió en el marco del lectorado, a partir de 1954, durante 3 años. A partir de 1978, el español se estudia como primera lengua extranjera, durante 4 años en los estudios de grado. En el curso escolar 2000-2001 se forma la Cátedra de literaturas hispánicas, mientras que la Cátedra de lengua y literatura española recibe el nombre de Cátedra de lengua española ${ }^{5}$.

Por tanto, según Soldatić (2011: 31) el año 1971 puede considerarse como el año en que comenzó el desarrollo profesional de los estudios hispánicos en la ex Yugoslavia, puesto que en Croacia el español todavía tenía estatus de segunda lengua.

En cuanto a la lexicografía como asignatura en los programas de estudio en Serbia y en Croacia, parece que no ha estado presente hasta hace poco. En Serbia, la asignatura Lexicografía del español fue introducida por la profesora Andjelka Pejović, primero en el Departamento de Hispanística de la Universidad de Kragujevac, como asignatura optativa en el programa de segundo ciclo (a partir del año académico 2010-2011), y luego en el Departamento de Estudios Ibéricos de la Universidad de Belgrado, como asignatura optativa en los estudios de grado (a partir del curso académico 2018-2019). En Croacia, nos consta que la profesora Ivana Lončar de la Universidad de Zadar se encarga de la asignatura Lexicografía y que dirige varios trabajos de fin de grado de este campo.

\section{BREVE PANORAMA DE LA LEXICOGRAFÍA EN SERBIA Y CROACIA ${ }^{6}$}

La labor lexicográfica referente a la lengua que se denominaba serbocroata / croataserbio se desarrolló en ambientes culturales muy diferentes, debido a circunstancias

\footnotetext{
${ }^{4}$ https://romanistika100.ffzg.unizg.hr/romanistika/ [consulta: 08/10/2019].

${ }^{5} \mathrm{http}: / /$ www.ffzg.unizg.hr/roman/spanjolski/katedre/katedra-za-spanjolski-jezik/ [consulta: 08/10/2019]

${ }^{6}$ Más información sobre la lexicografía serbia y la croata y las respectivas bibliografías está disponible en las siguientes obras: Franolić (1985), Katičić (1990), Musulin (1959), Putanec (1962) y Šipka (2000).
} 
históricas: la separación dentro de la iglesia, el Gran Cisma (en 1054), y, más tarde, la influencia occidental, en el caso del croata; la influencia oriental, más concretamente, la turca, en el caso del serbio. Šipka (2006) divide la lexicografía serbocroata en dos fases, una anterior a Vuk Stefanović Karadžić (el gran reformador del serbio y autor del primer diccionario de la lengua serbia, a principios del s. XIX), y otra posterior. En la primera, las lexicografías de ambas lenguas son independientes, siendo la croata claramente superior. Los orígenes de la lexicografía croata se remontan al siglo XV, aunque la labor práctica data de finales del siglo XVI. Los inicios de la lexicografía serbia se sitúan en la segunda mitad del siglo XVIII. La diferencia, sin embargo, no reside solamente en las fechas, sino también en la cantidad y la calidad, a favor de la croata. En la segunda fase, posterior a Vuk, las dos corrientes lexicográficas se funden, aunque hay diccionarios que en su título optan por el nombre de una lengua u otra (el serbio o el croata) (Šipka, 2006: 176). Esta simbiosis lexicográfica serbocroata duró hasta principios de los años 90 del siglo XX, cuando comienza una tercera fase, que Šipka (2006) denomina postyugoslava?

El año en que se sitúa el comienzo de la lexicografía croata es el 1595, cuando se publica el Dictionarium quinque nobilissimarum Europae linguarum, Latinae, Italicae, Germanicae, Dalmatiae \& Ungaricae, de Faust Vrančić (Musulin, 1959: 41; Šipka, 2006: 177). En la lexicografía serbia, se considera como primera obra lexicográfica el anexo a un diccionario latino-eslavoserbio en una gramática del latín, probablemente la de Zaharije Orfelin de 1766 (Šipka, 2006). La fase yugoslava comienza con la publicación del diccionario de la lengua serbia de Vuk Stefanović Karadžić (Srpski rječnik), en 1818. Según señala Šipka (2006: 183-184), este diccionario se fundamentó en la base de la lexicografía croata, e inició o anunció una práctica lexicográfica moderna. Tal vez el proyecto más significativo fue el iniciado a finales del siglo XIX, el diccionario Rječnik hrvatskoga ili srpskoga jezika de la Academia Yugoslava de Ciencia y Artes (JAZU) ${ }^{8}$. De esta segunda fase data también el gran tesauro titulado Rečnik srpskohrvatskog književnog i narodnog jezika, de la Academia Serbia de Ciencia y Artes (SANU), cuyo primer tomo fue publicado en 1959. Mientras que el diccionario de la JAZU recoge el léxico de la época anterior a Vuk Stefanović Karadžić, el de la SANU se basa en un corpus posterior a Vuk.

La lexicografía serbia hoy en día está algo parada, según Gortan Premk (2017: 301). Primero, porque hay pocos lexicógrafos, y luego porque la metodología no sigue el paso del desarrollo tecnológico; y afirma que «la historia del trabajo lexicográfico de una lengua es el reflejo de la historia política, social y cultural de los que hablan esa lengua» ${ }^{9}$ (Gortan Premk, 2017: 302). A pesar de que, según la autora, el serbio dispone de varios tipos de diccionarios de alta o muy alta calidad, es necesario confeccionar un diccionario de la lengua serbia estándar, que cubra el periodo que va desde la Segunda Guerra Mundial, puesto que las fases anteriores se han cubierto o se están cubriendo.

\footnotetext{
${ }^{7}$ Para más información véase Šipka (2002: 176-189).

${ }^{8}$ El primer cuaderno salió en 1880 y el primer tomo en 1882 , mientras que el último, $23^{\circ}$, fue publicado en el año 1976. El diccionario registra alrededor de 300.000 entradas.

${ }_{9}$ «Istorija leksikografije jednoga jezika odraz je političke, socijalne i kulturne istorije onih koji tim jezikom govore».
} 
En cuanto a la lexicografía bilingüe, Gortan Premk (2017: 307) considera que, en el caso del serbio, sería muy útil que los lexicógrafos serbios elaboraran la parte izquierda del diccionario, que serviría de base y facilitaría la confección de los diccionarios bilingües que parten del serbio. Naturalmente, estas nomenclaturas deberían actualizarse continuamente. La autora asimismo reclama como urgente la formación de lexicógrafos profesionales, por un lado, y el empleo de las nuevas tecnologías en todas las fases del trabajo, por otro (Gortan Premk, 2017: 308).

La lexicografía croata, como muestra Filipović (1998), encuadra muy bien en la lexicografía europea, con la que se desarrolla paralelamente. A estas conclusiones ha llegado mediante el análisis de los resultados de los principales lexicógrafos europeos, presentados y/o publicados en conferencias y revistas relevantes, y mostrando que los lexicógrafos croatas han abordado y abordan temas de la misma importancia y actualidad, tanto en el plano teórico como en el práctico (por ejemplo, el uso de las nuevas tecnologías y los corpus, las técnicas lexicográficas y los problemas concretos, etc.).

Todo parece indicar que la labor lexicográfica en Croacia es más fructífera, más visible en el ámbito europeo y que se desarrolla de una manera más sistemática e institucional. De ello se encarga, en primer lugar, el Leksikografski zavod Miroslav Krleža $^{10}$, fundado en 1950, y el Institut za hrvatski jezik i jezikoslovlje ${ }^{11}$, fundado en 1948, con el principal objetivo de terminar Rječnik hrvatskoga ili srpskoga jezika. En Serbia, es el Institut za srpski jezik ${ }^{12}$, fundado en 1947, el que se encarga de confeccionar diccionarios, además de trabajar en otras publicaciones y actividades relacionadas con la lengua serbia. Como puede verse en la página del Instituto, se fundó a partir del Departamento de Lexicografía, formado en 1893 por la Real Academia Serbia. Su proyecto de mayor envergadura es la elaboración del diccionario de la lengua literaria y popular serbocroata (Речник српскохрватског књижевног и народног језика). El primer volumen salió en 1959 y hasta ahora se han publicado 19 tomos, y se está finalizando el $20^{\circ}$. El diccionario constará en total de unos 35 tomos y tendrá más de 500.000 entradas $^{13}$. La calidad de este diccionario se califica como sumamente alta, y en algunos casos, hasta perfecta (Gortan Premk, 2017: 295).

La mejor base para la elaboración de un buen diccionario bilingüe es la existencia de un buen diccionario monolingüe de uso general, para cada una de las dos lenguas en cuestión; de lo contrario, el lexicógrafo no dispone de un registro de lexemas de una lengua y de sus correspondientes significados, o sea, de su descripción (Zgusta, 1991: 286-287). Asimismo, es imprescindible la formación de lexicógrafos, que, aunque no trabajen directamente en la confección de un diccionario, puedan çorientar y vigilar la realizacion de un trabajo lexicográfico (bilingüe) concreto.

\footnotetext{
${ }^{10}$ Hasta ahora ha publicado más de 250 enciclopedias, diccionarios y otras obras lexicográficas. Para más información véase http://www.lzmk.hr/

${ }^{11} \mathrm{http}: / / \mathrm{ihjj} . \mathrm{hr} / \mathrm{stranica} / \mathrm{o}-\mathrm{institutu/5/[consulta:03/11/2019]}$

${ }^{12} \mathrm{http}: / / \mathrm{www}$.isj.sanu.ac.rs/o-nama/o-institutu/ [consulta: 03/11/2019].

${ }^{13}$ En 2016 empezó la digitalización de este gran tesauro.
} 


\section{LOGROS LEXICOGRÁFICOS DEL HISPANISMO SERBIO Y EL CROATA}

Para que una oferta lexicográfica pueda caracterizarse como satisfactoria o no, es importante determinar, entre otras cosas, si los diferentes grupos de usuarios disponen de diccionarios que respondan a sus necesidades (Bratanić, 1996: 46). Es decir, debería haber diccionarios tanto para los que se dedican profesionalmente a una lengua extranjera (traductores, profesores, etc.), como para alumnos y estudiantes de distintas edades, como para aquellos que necesitan desenvolverse en un determinado ámbito técnico, sin que sean filólogos. Antes de proceder a la presentación de los diccionarios bilingües español-serbio/croata y serbio/croata-español vamos a recordar muy brevemente qué tipos de diccionarios existen.

La taxonomía de los diccionarios se hace según determinados criterios y, naturalmente, un mismo diccionario puede pertenecer a más de una categoría. Los criterios se diferencian ligeramente de un autor a otro. Por ejemplo, Porto Dapena (2002: 42-76) distingue, primero, entre diccionarios lingüísticos y no lingüísticos (enciclopedias); luego clasifica los diccionarios lingüísticos según: (1) la perspectiva temporal (diccionarios sincrónicos y diacrónicos), (2) el volumen (diccionarios monolingües, bilingües y plurilingües) y la extensión de las entradas (diccionarios generales y diccionarios particulares o restringidos), (3) el nivel o plano lingüístico contemplado (diccionarios de lengua, de norma y de discurso), (4) la microestructura (diccionarios descriptivos y no descriptivos), (5) la ordenación (diccionarios alfabéticos, ideológicos, de familias etimológicas, estadísticos, estructurales y mixtos), y (6) el soporte (diccionarios de papel y diccionarios electrónicos).

Campos Souto y Pérez Pascual (2003), a su vez, establecen los siguientes criterios: el número de lenguas, el eje temporal, el material léxico registrado, la densidad de la microestructura, el criterio purista, el eje sintagmático / el eje paradigmático, la ordenación de las entradas, la naturaleza pedagógica, la extensión y formato del inventario, y el soporte.

Kostić-Tomović (2017: 170) establece los siguientes criterios con los correspondientes tipos de diccionarios: (1) el soporte (diccionarios impresos y electrónicos o digitales), (2) la índole de la información (lingüísticos y no lingüísticos o enciclopedias), (3) el número de lenguas (monolingües, bilingües y plurilingües), (4) la independencia (independientes y dependientes, como glosarios, por ej.), (5) el enfoque y la estructura (semasiológicos, que pueden ser "normales" e inversos, y onomasiológicos, que pueden ser tesauros e ilustrados), y (6) el tipo de información (generales y especializados).

Esta última categoría (diccionarios generales y especializados) es muy heterogénea, y sobre todo los diccionarios especializados o especiales, también denominados particulares o restringidos, pueden ser muy variados (por ejemplo, diccionarios de sinónimos y de antónimos, combinatorios, fraseológicos, ortográficos, infantiles, escolares, de aprendizaje, terminológicos, etc.). Porto Dapena (2002: 59) recuerda que

los términos general y particular no suponen mayor ni menor número de entradas, sino una diferencia de amplitud en la esfera léxica considerada. Esto supuesto, diccionario general es el que estudia el léxico de una lengua en toda su amplitud, esto es, sin limitación alguna, mientras que un diccionario particular ${ }^{14} \mathrm{o}$ especial tan solo se ocupa

\footnotetext{
${ }^{14}$ Los diccionarios particulares o restringidos a veces se denominan también vocabularios (Porto Dapena, 2002).
} 
de una determinada parcela del vocabulario, respondiendo, por tanto, a una delimitación previa del conjunto léxico descrito.

El mismo autor explica que, teniendo en cuenta que el léxico es un sistema abierto, los diccionarios generales pueden ser exhaustivos y selectivos (Porto Dapena, 2002: 59), así que en los segundos entrarían, por ejemplo, los diccionarios manuales o diccionarios de bolsillo, que suelen usarse para una consulta rápida ${ }^{15}$. Un diccionario de bolsillo normalmente incluye las palabras de uso más frecuente y registra los significados más corrientes; «[s]e trata normalmente de una obra sin grandes pretensiones, de carácter elemental y frecuentemente de baja calidad, escrita generalmente con puros fines comerciales, y dirigida generalmente a un público joven, no demasiado exigente» (Porto Dapena, 2002: 61). Un subtipo importante de diccionario de bolsillo es el diccionario turístico.

En lo que se refiere al diccionario bilingüe, «[e]l propósito principal del diccionario bilingüe reside en establecer la relación entre las unidades léxicas de una lengua con aquellas unidades léxicas de otra lengua que se muestran iguales en su significado léxico» ${ }^{16}$ (Zgusta 1991: 275). Según Zgusta (1991: 280),

[1]a dimensión probablemente más importante de la tipología de los diccionarios bilingües reside en la intención del lexicógrafo al redactar el diccionario: como ayuda en la comprensión de textos en la lengua origen, o como descripción de la lengua origen, o como ayuda en la producción de textos en la lengua meta ${ }^{17}$.

Añade que, aunque el lexicógrafo suele hacer hincapié en uno de los propósitos mencionados, intenta tener en cuenta también los demás, por lo que un mismo diccionario normalmente satisface distintas necesidades.

Los diccionarios bilingües muchas veces son de un volumen no muy grande, no solo en cuanto al número de las entradas sino también en lo que se refiere a la información en el cuerpo del artículo lexicográfico. Hay más tipos de diccionarios bilingües que de monolingües, según Zgusta (1991: 303).

En lo que se refiere al inicio de la presencia del español en la lexicografía de las comunidades lingüísticas serbia y croata, a partir del corpus extraído podemos decir que se sitúa en la segunda fase, la yugoslava.

Cronológicamente, el diccionario de español más antiguo en ambos países es el Španjolsko-hrvatski priručni rječnik ('diccionario manual español-croata') del literato y traductor croata Iso Velikanović, publicado en Zagreb, en 1928, que consta de 242 páginas, y luego el 'diccionario manual croata-español', o sea Hrvatsko-španjolski priručni rječnik, publicado por el mismo autor, también en Zagreb, en 1929 (343 + XLI páginas). Puede decirse que es un diccionario particular o restringido, de aprendizaje, porque se confecciona para complementar un manual de español previamente elaborado,

\footnotetext{
${ }^{15}$ A diferencia de un diccionario tesauro, por ejemplo, un diccionario manual «no suele llevar citas o textos tomados como ejemplos» (Porto Dapena, 2002: 60-61).

${ }^{16}$ «Glavna je namjena dvojezičnog rječnika da uspostavlja vezu između leksičkih jedinica jednog jezika sa onim leksičkim jedinicama drugog jezika koje su jednake u svom leksičkom značenju.»

${ }^{17}$ «Vjerovatno najvažnija dimenzija tipologije dvojezičnih rječnika sastoji se u leksikografovoj namjeri da sastavi rječnik: kao pomagalo u shvatanju tekstova u izvorišnom jeziku, ili kao opis izvorišnog jezika, ili kao pomoć za stvaranje tekstova na odredišnom jeziku».
} 
titulado Upute $u$ španjolski jezik. Como indica el propio autor, se basa en diccionarios grandes y recoge lo necesario para un lenguaje conversacional, igual que para lecturas periodísticas o literarias. El autor mismo alega que es el primer diccionario de español en el país, por lo que considera que será útil a todo el que se dedique a esta lengua (Velikanović, 1928: 4). Para facilitar el aprendizaje y el uso de los verbos españoles, el autor marca cada verbo en el diccionario con un número que corresponde al tipo de conjugación, y las conjugaciones se dan en el mencionado manual. Velikanović se detiene también en las diferencias «entre el alfabeto croata y el español», explicando la pronunciación y la escritura de las letras y los sonidos más relevantes. Algunas veces, como en el caso del sonido interdental $[\Theta]$, las explicaciones son muy plásticas y de ahí muy prácticas. Otro elemento que llama la atención y confirma el carácter didáctico del diccionario es la marcación de la sílaba tónica (con una tilde) en todas las palabras de entrada. Las mismas características y los mismos elementos se dan en el segundo volumen del diccionario, croata-español, publicado en 1929. Con esta obra el autor pretende aportar palabras pero también «fraseología», o sea, locuciones importantes para la lengua en cuestión. El diccionario incluye un anexo con ejemplos de las conjugaciones verbales en español, modelos que están numerados, y que se adscriben, según el tipo, a cada uno de los verbos que figuran en el diccionario.

Un segundo diccionario, desde el punto de vista cronológico, es el diccionario de bolsillo con una breve gramática española Džepni špansko-srpskohrvatski rečnik sa kratkom gramatikom španskog jezika, de Branislav Grujić, publicado en el año 1962 entre Belgrado (Serbia) y Cetinje (Montenegro). El diccionario recoge 30.000 palabras y tiene 392 páginas. Después de la separación de las ex repúblicas yugoslavas, se publica como un diccionario español-serbio (Džepni špansko-srpski rečnik sa kratkom gramatikom španskog jezika). En dirección contraria, serbocroata-español, el diccionario se publica por primera vez en el año 1965, para titularse después de los años 90 'diccionario serbio-español'.

En 1971 sale a la luz en Zagreb Španjolsko-hrvatskosrpski rječnik s osnovama španjolske gramatike $i$ španjolskog trgovačkog dopisivanja (XV+1132 páginas), bajo la autoría de Vojmir Vinja, en colaboración con Ratibor Musanić.

Vojmir Vinja es autor, junto a Rudolf Kožljan, del diccionario Langenscheidtov univerzalni rječnik. Španjolsko-hrvatskosrpski, hrvatskosrpsko-španjolski, publicado en 1972 en Zagreb. Conviene recordar que Vinja es uno de los romanistas croatas más significativos, en la época posterior a la del famoso lingüista Petar Skok ${ }^{18}$.

Un diccionario terminológico, titulado Leksikon društveno-političke i samoupravne terminologije: srpskohrvatski-španski, fue publicado en 1977 por Novak Strugar (Beograd).

A partir de los años 90 del siglo pasado, como se ha dicho, comienza la fase postyugoslava en la lexicografía y la lingüística en general en Serbia y en Croacia. A continuación, vamos a presentar los logros alcanzados en esa etapa: desde principios de los años 90 del siglo XX hasta la actualidad. Veremos, en primer lugar, que se observa

\footnotetext{
${ }^{18}$ https://romanistika100.ffzg.unizg.hr/romanistika/ [consulta: 08/10/2019].
} 
un cambio del nombre de la lengua en los títulos, lo cual se debe, naturalmente, a la adaptación a las respectivas políticas lingüísticas.

\subsection{Diccionarios español-serbio / serbio español}

Los diccionarios bilingües del español y el serbio publicados en Serbia a partir de los años 90 del siglo XX son por lo general diccionarios generales selectivos, en terminología de Porto Dapena (2002), muchas veces de bolsillo o manuales, aunque no contengan esa calificación en el título. También hay un cierto número de diccionarios particulares (terminológicos, didácticos, ilustrativos, etc.). A continuación, vamos a presentar, primero, los diccionarios generales selectivos, $\mathrm{y}$, después, los particulares.

El único diccionario de uso general, pero de carácter selectivo, publicado en la fase yugoslava, es el diccionario de bolsillo de Branislav Grujić (español-serbocroata, 1962; serbocroata-español, 1965). El mismo diccionario siguió publicándose en los años 90 , y también en el siglo XXI, aunque con el nombre serbio en vez de serbocroata. El mismo autor publicó en 2001 el Nuevo diccionario estándar español-serbio serbioespañol / Novi standardni rečnik špansko-srpski srpsko-španski (Nikšić), que va por la cuarta edición. Este diccionario bidireccional contiene, además, un apéndice gramatical del español, otro apéndice de sinónimos (solo en español), y un apéndice de diccionario ilustrativo, en las dos lenguas.

Otro diccionario de bolsillo fue publicado por Zoja e Ivana Stojanović, en 1995: Džepni srpsko-španski rečnik (Beograd-Svjetlost). En 1998, Jasmina Boričić publicó un diccionario bidireccional, con una breve gramática del español (Špansko-srpski $i$ srpsko španski rečnik (sa osnovama španske gramatike, Zemun). Este diccionario es el que más ediciones lleva de todos (10, según los datos de los que disponemos), seguido por el diccionario estándar de Branislav Grujić y el diccionario de Vojislav Nikolić, con 5 ediciones cada uno. En 2004, Marijana Panžić y Biljana Kovačević publican Špansko-srpski i srpsko-španski rečnik (Beograd); en 2005, aparece Špansko-srpski / srpsko-španski rečnik (Beograd), de Vojislav Nikolić; Veljko Nikitović es el autor de Srpsko-španski / špansko-srpski rečnik sa gramatikom (Beograd), publicado en 2013; Aleksandra Golubović y Vesna Zorić son autoras de Srpsko španski rečnik osnovnih reči i izraza sa izgovorom (Beograd), de 2015; finalmente, Španski džepni rečnik (ne samo za početnike) fue publicado en Novi Sad en el año 2017.

En cuanto a los diccionarios particulares, el primero en salir fue Business rečnik špansko-srpski, srpsko-španski de Carmen Vegas de Spalajković, en 1997 en Belgrado. Cinco años después (en 2002) apareció también en Belgrado un diccionario plurilingüe que incluye el español y el inglés: Rečnik i razgovornik / Vocabulario y frases cotidianas / Vocabulary and Everyday Phrase (srpski, španski, engleski) (editor Stanoje Jovanović; traducción al inglés Darinka Stojanović; traducción al español Nadežda Zarubica; ilustraciones Djordje Gorbunov; fotografías Radovan Popović). En el mismo año se presentó el diccionario ilustrado del español Španski slikovni rečnik (Beograd), de Bruno Vajs y Zoran Davidović. Al año siguiente, 2003, se publicó un diccionario didáctico, de pequeño volumen, titulado Špansko-srpski srpsko-španski didaktički rečnik / Diccionario didáctico español-serbio serbio-español. Dragana Tošić es autora de Srpsko-španski rečnik pravnih i poslovnih termina / Diccionario de términos jurídicos y de negocios ser- 
bio-español, publicado en Belgrado en 2005. En el año 2006 se publicaron 3 diccionarios particulares: Biljana Romčević se encargó de la publicación del diccionario ilustrado del español Ilustrovani rečnik španskog jezika (Beograd-Novi Sad, en cirílico); a Milutin Stojanović se debe un diccionario terminológico serbio-español, titulado Rečnik fraza $i$ opštih izraza: srpsko-španski: 55.000 terminoloških jedinica (Beograd); Carmen Vegas de Spalajković, por su parte, publicó un diccionario idiomático bidireccional, titulado Rečnik idioma i fraza: špansko-srpski srpsko-španski (Beograd). Parece que hubo una pausa de 8 años en la publicación de diccionarios particulares, después de la cual Milomir Kragović editó en 2014 en Belgrado Džepni rečnik srpsko-španski, mientras que Nenad Atanasković editó en esta misma capital el diccionario ilustrado Dvojezični slikovni rečnik špansko-srpski, de cuya traducción se encargaron Dubravka Trišić y Svetlana Babović.

En el año 2018, en la casa editorial Zavod za udžbenike de Belgrado, Luiza Valožić publicó un diccionario escolar de gran importancia: Špansko-srpski / srpsko-španski rečnik za osnovnu školu (cirílico) ${ }^{19}$. Finalmente, ese mismo año, Jasna Vidić, Danijela Đorović y Marina Nikolić publicaron tambien en Belgrado Višejezični terminološki rečnik istorije umetnosti srpsko-francusko-italijansko-španski sa dvojezičnim glosarima (en cirílico).

En Serbia se han publicado varios diccionarios plurilingües que incluyen el serbio y el español, pero, a diferencia de los mencionados arriba, son obras previamente publicadas fuera del país, que contenían ya el español, en las que se incluyen las unidades equivalentes en serbio. De todas formas, al final del trabajo ofrecemos una lista con estos diccionarios.

En Pejović (2013) vemos que la lexicografía bilingüe es el punto débil del hispanismo serbio, que tiene una actividad docente y traductora muy desarrollada, y se muestra muy activo también en ámbitos como la internacionalización, las actividades culturales y las editoriales. Reflexionando acerca de la falta de un mayor y más variado número de diccionarios bilingües, la autora señala lo siguiente:

[u]na de las razones, seguramente, reside en lo arduo y duradero que es el trabajo de confeccionar un diccionario, por muy pequeño volumen que tenga. Entre demás argumentos también podría aducirse la baja recompensa económica para el autor, y el bajo mérito académico, hasta menor que en el caso de los materiales docentes. Asimismo, se intuye cierto miedo a una posible crítica, por parte de los demás hispanistas, sobre todo aquellos que se dedican profesionalmente a la traducción. Finalmente, la falta de corpus lingüísticos, que permitan conocer o comprobar el comportamiento de las unidades léxicas en diferentes contextos, también es un obstáculo más en la realización de la labor lexicográfica (Pejović, 2013: 56).

La autora también indica la necesidad de la formación de lexicógrafos, por ejemplo mediante la introduccion en el programa de estudio de la asignatura Lexicografía del español, que tal vez «sirva de punto de partida con el que se animen futuros especialistas en esta materia» (Pejović, 2013: 56).

\footnotetext{
${ }^{19}$ La misma casa editorial publicó unos años antes los manuales de español para la escuela primaria. Se trata de los paquetes didácticos Hola, amigos, del primero al cuarto curso de primaria, y ¿Hablamos?, del quinto al octavo de primaria.
} 
Conviene aquí llamar la atención sobre la muy fructífera labor traductológica de los hispanistas serbios, «que cada vez se caracteriza por una mayor calidad, debido a la mejor formación que reciben los hispanistas serbios. Todo ello lleva a que se traduzcan más obras y de autores y épocas diferentes» (Pejović, 2013: 55) ${ }^{20}$. Debería encontrarse la manera de aprovechar estas traducciones para la elaboración de una base de datos, que serviría como corpus representativo no solo para la confección de los diccionarios, sino también para cualquier investigación lingüística referente al serbio y el español.

\subsection{Diccionarios español-croata / croata-español}

El diccionario bilingüe español-croata de uso general del famoso lingüista croata Vojmir Vinja siguió publicándose también en la época postyugoslava, por la misma casa editorial: Španjolsko-hrvatski rječnik s osnovama španjolske gramatike $i$ španjolskog trgovačkog dopisivanja, Zagreb. Hasta la actualidad, ha tenido 6 ediciones, siendo la última del año 2017. También se siguió publicando en Zagreb el diccionario Španjolskohrvatski, hrvatsko-španjolski, de Vojmir Vinja y Rudolf Kožljan.

Aparte de los diccionarios de Vinja, se publicaron algunos más, aunque no con el mismo alcance y exhaustividad. En 1999, Petar Požar publica Univerzalni rječnik hrvatsko-španjolski, španjolsko-hrvatski: gramatika. Un año más tarde, en 2000, Nensi Pekić Matleković firma la autoría del diccionario Španjolsko-hrvatski rječnik (Zagreb). Spomenka Husar es la autora de Univerzalni rječnik španjolsko-hrvatski, hrvatskošpanjolski, publicado en el año 2003. Dos años después (2005) se publica en Zagreb Hrvatsko-španjolski praktični rječnik, de Cvjetanka Božanić. Este diccionario ha tenido varias ediciones desde entonces. Ruben Cvjetković Katušić publica un diccionario de dos volúmenes, titulado Hrvatsko-španjolski rječnik. 2 vols: A-O, P-Ž (Punta Arenas), en 2012. Finalmente, del año 2013 data el diccionario manual Hrvatsko-španjolski priručni rječnik (Split), cuyas autoras son Ivana Bašić e Silvija Vlahovec.

En lo que se refiere a los diccionarios particulares, hemos registrado tres: (1) Španjolski za putnika: vodič i džepni rječnik: hrvatsko-španjolski, španjolsko-hrvatski (Zagreb, 2001), de Mirjana Jurčić y Ana Coce Mavar; (2) Komparativni rječnik hrvatskih $i$ španjolskih poslovica (Dubrovnik, 2001), de Rosa María Mascarell Canet y Miho Šiša Konavljanin; y (3) Rječnik hrvatsko-španjolski i španjolsko-hrvatski leksičkoga priručnika HRump 1 / Diccionario croata-español y español-croata que acompaña al libro de texto HRump 1 (Zagreb, 2012), de las autoras Maša Musulin, Gordana Dobravac y Zrinka Jelaska.

En este último grupo cabe incluir dos diccionarios plurilingües muy importantes: el de Tomislav Ladan (editor), de 8 volúmenes, Osmojezični enciklopedijski rječnik: hrvatski, ruski, engleski, njemački, francuski, italijanski, španjolski, latinski. 8 vols. (Zagreb, 1987-2010), y el de Željka Fink-Arsovski et al. del año 2016, Hrvatsko-

\footnotetext{
${ }^{20}$ Por ejemplo, la edición «Las mejores novelas españolas de la segunda mitad del siglo XX», traducidas entre 2006 y 2010 bajo la dirección de Dalibor Soldatić del Departamento de Estudios Ibéricos, «Clásicos del Realismo español», publicados en 2012 bajo la coordinación de Vladimir Karanović, del mismo departamento, o la edición «Biblioteca Hispania», de 2013 hasta la actualidad, cuyos coordinadores son Željko Donić e Izabela Beljić, del Departamento de Estudios Ibéricos de Belgrado, y Snežana Jovanović, recién incorporada al Departamento de Hispanística de Kragujevac.
} 
romansko-germanski rječnik poredbenih frazema (Zagreb). Igual que en el caso de la situación lexicográfica plurilingüe en Serbia, también en Croacia se han publicado algunos diccionarios plurilingües que contienen el español y los equivalentes en croata (adjuntamos su listado a este trabajo, Apéndice 2).

\section{CONCLUSIÓN}

Los diccionarios bilingües (español-serbio / serbio-español, español-croata / croataespañol) publicados tanto en Serbia como en Croacia son diccionarios impresos. Más concretamente, son diccionarios generales selectivos y diccionarios particulares (sobre todo terminológicos, pero también diccionarios de aprendizaje).

El diccionario de mayor envergadura sigue siendo, en nuestra opinión, el de Vojmir Vinja. Los demás diccionarios de uso general son mucho más selectivos y ofrecen una información menos completa. Prevalecen los diccionarios de menor tamaño, lo cual puede entenderse principalmente como consecuencia de las desfavorables condiciones de trabajo en el ámbito de la lexicografía en ambos países: la labor lexicográfica no está (lo suficientemente) valorada, ni académica ni económicamente, a pesar de que supone un trabajo arduo, largo y muy dedicado.

La posible clave tal vez esté en las nuevas tecnologías, con las que se van creando diccionarios híbridos, o sea, que hacen que disminuya o hasta desaparezca la diferencia entre los distintos tipos de diccionarios. Pero, aun así, el factor humano no puede pasarse por alto, y aparte de conocimientos tecnológicos, se ha de disponer de conocimientos lexicográficos y lingüísticos en general. Aunque no nos hemos ocupado de la calidad de los diccionarios y la formación de sus autores, queda bastante patente que la gran mayoría de los autores o editores no tienen formación lexicográfica, lo cual se comprueba, en cierta medida, a través de los programas de estudio en los respectivos departamentos, pero también en las casas editoriales, que a veces son editoriales pequeñas, no especializadas en este tipo de publicaciones. A esto habría que añadir la falta de evaluación o revisión de los diccionarios por parte de expertos, con los que suelen contar solo las editoriales con más prestigio.

A pesar de todos los problemas o precisamente teniendo en cuenta los problemas que afrontan y los obstáculos con los que se encuentran los autores de diccionarios, que muchas veces no tienen ningún tipo de apoyo y reciben poca o ninguna recompensa, podemos terminar este trabajo con la cita de Samuel Johnson que encabeza este artículo : «Los diccionarios son como los relojes: el peor es mejor que ninguno, pero del mejor uno no puede esperar que sea del todo preciso».

\section{REFERENCIAS BIBLIOGRÁFICAS}

BRATANIĆ, Maja (1996): «Suvremena hrvatska dvojezična leksikografija u svjetlu korisničkih potreba (preliminarno istraživanje)», $S L, 41 / 42$, pp. 45-61. 
CAmpos Souto, Mar y José Ignacio Pérez PAscual (2003): «El diccionario y otros productos lexicográficos», en Antonia María Medina Guerra, coord., Lexicografía española, Barcelona, Ariel, pp. 53-78.

FILIPOVIĆ, Rudolf (1998): «Hrvatska leksikografija u okviru europske leksikografije», Filologija, 30-31, pp. 1-8.

FrANOLIĆ, Branko (1985): A Bibliography of Croatian Dictionaries. Paris, Nouvelles editions latines.

GORTAN PREMK, Darinka (2017): «Srpska leksikografija danas», Južnoslovenski filolog, LXXIII, 3-4, pp. 291-313.

KATIČIĆ, Radoslav. (1990): «Serbokroatische Lexicographie», en F. J. Hausmann, O. Reichmann, H. E. Wiegand y Ladislav Zgusta, eds., Wörterbücher / Dictionaries / Dictionnaires: Ein internationales Handbuch zur Lexikographie / An International Encyclopedia of Lexicography / Encyclopédie internationale de lexicographie, Berlin-New York, Walter de Gruyter, 2, pp. 2288-2296.

Kostić-Tomović, Jelena (2017): Savremena nemačka leksikografija. Nemački i srpskonemački rečnici u prvoj polovini 21. veka: tipovi, vrste informacija i upotreba, Beograd, Fokus.

Musulin, Stjepan (1959): «Hrvatska i srpska leksikografija», Filologija, 2, pp. 1-63.

PEJOVIĆ, Andjelka (2013): «Alcances y perspectivas del español en Serbia», Acta Hispánica, XVIII, pp. 49-60.

Porto DAPENA, José-Álvaro (2002): Manual de técnica lexicográfica, Madrid, Arco/Libros.

PUTANEC, Valentin (1962): «Leksikografija», en Enciklopedija Jugoslavije, 5 (Jugos-Mak), Zagreb, Leksikografski zavod FNRJ, pp. 503-511.

SOLDATIĆ, Dalibor (2011): «Hispanistika u svetu i u Srbiji», en Dalibor Soldatić y Željko Donić, Svet hispanistike. Uvod u studije, Beograd, Zavod za udžbenike, pp. 7-37.

StoJAnOvić, Jasna (2010): «Cervantes en Serbia», Colindancias, 1, pp. 40-47.

ŠIPKA, Danko (2000): A Bibliography of Serbo-Croatian Dictionaries: Serbian, Croatian, and Bosnian Muslim, Springfield, Dunwoody Press.

ŠIPKA, Danko (2006): Osnovi leksikologije i srodnih disciplina, Novi Sad, Matica srpska.

ZGusta, Ladislav (1991): Priručnik leksikografije, traducción de Danko Šipka, Sarajevo, Svjetlost.

\section{APÉNDICE 1}

DICCIONARIOS BILINGÜES DEL ESPAÑOL Y EL SERBIO O EL CROATA

(en orden cronológico, según la primera edición)

FASE YUGOSLAVA (hasta los años 90 del siglo XX)

1928: VeliKANOVIĆ, Iso, Španjolski-hrvatski priručni rječnik, Zagreb, St. Kugli.

1929: VeliKANOVIĆ, Iso, Hrvatsko-španjolski priručni rječnik, Zagreb, St. Kugli.

1962: GRUJIĆ, Branislav, Džepni špansko-srpskohrvatski rečnik sa kratkom gramatikom španskog jezika, Beograd-Cetinje, Prosveta-Obod.

1965: GRUJIĆ, Branislav, Džepni srpskohrvatsko-španski rečnik, Beograd-Cetinje, Prosveta-Obod.

1971: VINJA, Vojmir y Ratibor MUSANIĆ, Španjolsko-hrvatskosrpski rječnik s osnovama španjolske gramatike i španjolskog trgovačkog dopisivanja, Zagreb, Školska knjiga. 
1972: VINJA, Vinja y Rudolf KožLJAN, Langenscheidtov univerzalni rječnik. Španjolskohrvatskosrpski, hrvatskosrpsko-španjolski, Zagreb, Mladost.

1977: STRUGAR, Novak, Leksikon društveno-političke i samoupravne terminologije: srpskohrvatski-španski, Beograd, APS.

FASE PostyUgosLaVa (a partir de los años 90 del siglo XX)

\section{SERBIO}

... ${ }^{21}$ 1994: GRUJIĆ, Branislav. Džepni špansko-srpski rečnik sa kratkom gramatikom španskog jezika, Cetinje, Obod.

...1999: GRUJIĆ, Branislav. Džepni srpskošpanski rečnik, Cetinje-Beograd, ObodDraganić.

1995: STOJANOvić, Zoja e Ivana StOJANOvić, Džepni srpsko-španski rečnik, Beograd, Pirg.

1997: Vegas de SpalajKović, Carmen, Business rečnik špansko-srpski: srpskošpanski, Beograd, Ž. Albulj.

1998: BORIČIĆ, Jasmina, Špansko-srpski $i$ srpsko španski rečnik (sa osnovama španske gramatike), Zemun, JRJ.

2001: GRUJIĆ, Branislav. Nuevo diccionario estándar español-serbio serbio-español / Novi standardni rečnik špansko-srpski srpsko-španski, Nikšić, Jasen.

2002: VAJS, Bruno y Zoran DAVIDOVIĆ, Španski slikovni rečnik, Beograd, Alnari, Ateneum.

2003: Špansko-srpski srpsko-španski didaktički rečnik / Diccionario didáctico español-serbio serbio-español, Beograd, Foto futura.

2004: PANŽıć, Marijana y Biljana KOVAČEVIĆ, Špansko-srpski $i$ srpskošpanski rečnik, Beograd, Duška (cirílico) ${ }^{22}$.

2005: TošIĆ, Dragana, Srpsko-španski

\section{CROATA}

...1991: VINJA, Vojmir. Śpanjolskohrvatski rječnik s osnovama španjolske gramatike $i$ španjolskog trgovačkog dopisivanja. 3. izd., Zagreb, Školska knjiga (6 ediciones hasta 2019).

1999: POŽAR, Petar, Univerzalni rječnik hrvatsko-španjolski, španjolsko-hrvatski: gramatika.

...2000: VINJA, Vojmir y Rudolf KOŽLJAN, Španjolsko-hrvatski, hrvatsko-španjolski, Zagreb, Naklada Nediljko Dominović.

2000: Pekić Matleković, Nensi, Španjolsko-hrvatski rječnik, Zagreb, Genesis.

2001: JURČIĆ, Mirjana y Ana COCE MAVAR, Španjolski za putnika: vodič $i$ džepni rječnik: hrvatsko-španjolski, španjolsko-hrvatski, Zagreb, Školska knjiga.

2001: Mascarell CANet, Rosa Maria y Miho Šš̌s Konavluanin, Komparativni rječnik hrvatskih $i$ španjolskih poslovica. Dubrovnik, edición propia.

2003: HUSAR, Spomenka, Univerzalni rječnik španjolsko-hrvatski, hrvatskošpanjolski, Zagreb, Mozaik knjiga.

2005: BožANIĆ, Cvjetanka, Hrvatskošpanjolski praktični rječnik, Zagreb, Školska knjiga.

2012: CVJETKOVIĆ KATUŠIĆ,

\footnotetext{
${ }^{21}$ Los puntos suspensivos delante del año de publicación indican que el diccionario había sido publicado antes, o sea, en la fase yugoslava.

${ }^{22}$ Puesto que en serbio se usan dos alfabetos, el cirílico y el latino, señalamos entre paréntesis cuando, en el diccionario correspondiente, se ha usado el cirílico.
} 
rečnik pravnih i poslovnih termina / Diccionario de términos jurídicos y de negocios serbio-español, Beograd, Službeni glasnik.

2005: NiKOLIĆ, Vojislav, Špansko-srpski / srpsko-španski rečnik, Beograd, Jasen.

2006: ROMČEVIĆ, Biljana, Ilustrovani rečnik španskog jezika, Beograd-NoviSad, Teatar Za-Liber (cirílico).

2006: Stojanović, Milutin, Rečnik fraza $i$ opštih izraza: srpsko-španski: 55.000 terminoloških jedinica, Beograd, Građevinska knjiga.

2006: Vegas de SPALAJKović, Carmen, Rečnik idioma i fraza: ‘̌pansko-srpski srpsko-španski, Beograd, Megatrend univerzitet.

2013: NiKITOVIĆ, Veljko, Srpsko-španski / špansko-srpski rečnik sa gramatikom, Beograd, Book.

2014: Džepni rečni srpsko-španski, Beograd, Jasen (cirílico).

2014: Dvojezični slikovni rečnik (španskosrpski), Beograd, Vulkan izdavaštvo.

2015: GoluBOVIĆ, Aleksandra y Vesna ZORIĆ, Srpsko španski rečnik osnovnih reči i izraza sa izgovorom, Beograd, Vulkan izdavaštvo.

2017: Španski džepni rečnik (ne samo za početnike), Novi Sad, Lingea.

2018: VALOŽIĆ, Luiza, Špansko-srpski / srpsko-španski rečnik za osnovnu školu, Beograd, Zavod za udžbenike (cirílico).
Ruben, Hrvatsko-španjolski rječnik. 2 vols: A-O, P-Ž, Punta Arenas, edición propia.

2012: Musulin, Maša, Gordana DOBRAVAC y Zrinka JELASKA, Rječnik hrvatsko-španjolski $i$ španjolsko-hrvatski leksičkoga priručnika HRump 1 / Diccionario croata-español y españolcroata que acompaña el libro de texto HRump 1, Zagreb, Hrvatsko filološko društvo.

2013: BAŠIĆ, Ivana y Silvija VLAHOVEC, Hrvatsko-španjolski priručni rječnik, Split, Slobodna Dalmacija.

APÉNDICE 2:

DICCIONARIOS PLURILINGÜES QUE INCLUYEN EL ESPAÑOL Y EL SERBIO O EL CROATA (en orden cronológico, según la primera edición)

FASE YUGOSLAVA (hasta los años 90 del siglo XX)

1952: Ilustrirani tehnički rječnik: hrvatski, njemački, engleski, francuski, talijanski, španjolski, ruski. Elementi strojeva / Maschinenelemente / machine elements/ 
elements des machines/ elementi di macchine/ organos de maquinas/ detali mašin, Zagreb, Tehnička knjiga.

1960: Ilustrirani tehnički rječnik: hrvatski, njemački, engleski, francuski, talijanski, španjolski i ruski. 1. izd, Zagreb, Tehnička knjiga.

1969: SIMEON, Rikard y Vlatko PAVLETIĆ, Enciklopedijski rječnik lingvističkih naziva na 8 jezika: hrvatsko-srpski, latinski, ruski, njemački engleski, francuski, talijanski, španjolski. I: A-O. 1. Izd, Zagreb, Matica hrvatska.

1969: SiMEON, Rikard y Vlatko PAVLETIĆ, Enciklopedijski rječnik lingvističkih naziva na 8 jezika: hrvatsko-srpski, latinski, ruski, njemački engleski, francuski, talijanski, španjolski. II: P-Ž. 1. izd. Zagreb: Matica hrvatska, 1969.

1987: LADAN, Tomislav, Osmojezični enciklopedijski rječnik: hrvatski ili srpski, ruski, engleski, njemački, francuski, talijanski, španjolski, latinski. Vol. 1: A-E, Zagreb, Jugoslavenski leksikografski zavod Miroslav Krleža.

1989: BAKRAČ, Ksenija,Nautički rječnik: hrvatski-talijanski-francuski-engleskišpanjolski-njemački, Samobor, Zagreb.

1991: Višejezični pravno-ekonomski rečnik: srpskohrvatski, slovenački, makedonski, ruski, engleski, nemački, francuski, italijanski i španski: 768 termina i izraza iz Zakona o stranim ulaganjima i Zakona o preduzećima, Beograd, Udruženje naučnih i stručnih prevodilaca Srbije.

FASE POSTYUGOSLAVA (a partir de los años 90 del siglo XX)

\section{SERBIO}

1993: Opšti leksikon železničkih stručnih izraza: francuski, nemački, engleski, italijanski, španski, srpski, Beograd, Zavod za novinsko-izdavačku i propagandnu delatnost JŽ (4. ${ }^{\mathrm{a}}$ ed.).

1996: Međunarodni elektrotehnički IEC rečnik sa terminima na srpskom jeziku: elektroenergetika, elektronika $i$ telekomunikacije. Knj. 2 (francuski, engleski, ruski, nemački, španski, italijanski, holandski, poljski, švedski, srpski), Beograd, Savezni zavod za standardizaciju (3 tomos en 1996 y 2 tomos en 1997, pero el español está solo en el $2^{\circ}$ ).

1996: Rečnik železničkih stručnih izraza: francusko-nemačko-englesko-italijanskošpansko-srpski, Beograd, Želnid.

\section{CROATA}

1995: Goursau, Henri, Monique GOURSAU y Jasna BILINIĆZUBAK, Europski rječnik: hrvatskoenglesko-njemačko-francusko-talijanskošpanjolski, Zagreb, Mozaik knjiga.

**23 ...1995:

LADAN, Tomislav, Osmojezični enciklopedijski rječnik: hrvatski, ruski, engleski, njemački, francuski, talijanski, španjolski, latinski. Vol. 2, F-K, Zagreb, Leksikografski zavod Miroslav Krleža; vol. 3, L-NA (2000), vol. 4 NE-O (2002), vol. 5, P-Prih (2004), vol. 6 Prija-R (2007), vol. 7 S- S (2008), vol. 8 T-Ž (2010).

2003: JENY, Ruđer y Jelena BERIĆ, Petojezični slikovni rječnik:

\footnotetext{
${ }^{23}$ Los dos asteriscos delante del año de publicación del diccionario plurilingüe indican que el diccionario no ha sido traducido al serbio / croata sino que es una creación lexicográfica original.
} 
1997: REJ, Kenet y Ričard SAUTERN, Internacionalni rečnik pozorišnih termina: srpski, engleski, francuski, nemački, italijanski, španski, holandski, švedski, Beograd, Gea.

1998: GURSO, Anri, Evropski rečnik (srpski, engleski, nemački, francuski, italijanski, špansk), Beograd, Narodna knjiga-Alfa.

2002: Rečnik i razgovornik / Vocabulario y frases cotidianas / Vocabulary and Everyday Phrase (srpski, španski, engleski), Beograd, YU Marketing Press.

2003: Fudbalski rečnik / Footbal Dictionary / Dictionnaire du football / Diccionario del fútbol: srpsko-englesko-francusko-španski, Beograd, A. Mihajlović, 2003.

2004: Maletin, Stevan, Timotej Čobić, Vladimir KUNC y Milanko BEKVALAC, Višejezički rečnik ribarstva (engleskofrancusko-nemačko-špansko-srpski)

Multilingual Dictionary of Fishery (englishfrench-german-spanish-serbian)

Dictionnaire polyglote des pêches (anglaisfrançais-allemand-espagnol-serbe)

Mehrsparachiges Wörterbuch der Fischerei (englisch-französisch-deutsch-spanischserbisch) / Diccionario poligloto de la pesca (inglés-francés-alemán-español-serbio), Novi Sad, Poljoprivredni fakultet.

2006: Rečnik EUROVOC: višejezično izdanje: srpski, engleski, francuski, nemački, italijanski, španski, Beograd, Institut za međunarodnu politiku i privredu (cirílico).

**2018: Vidić, Jasna, Danijela Đorović y Marina NiKOLIĆ, Višejezični terminološki rečnik istorije umetnosti srpsko-francuskoitalijansko-španski sa dvojezičnim glosarima, Beograd: Filozofski fakultet, Univerzitet u Beogradu (cirílico). hrvatski-engleski-njemački-španjolskifrancuski, Zagreb, Znanje.

**2016: FinK-ARSOVSKI, Željka et al., Hrvatsko-romansko-germanski rječnik poredbenih frazema, Zagreb: Knjigra. 